\title{
Influence of Substrate Properties on the Impact Resistance of WC Cermet Coatings
}

\author{
S. Osawa, T. Itsukaichi, and R. Ahmed
}

(Submitted September 29, 2004; in revised form May 27, 2005)

\begin{abstract}
This research delivers a generic understanding of the design and integrated performance of the coatingsubstrate systems under impact loading, and comprehends the understanding of underpinning failure mechanisms. Repeated severe impacts to the coatings often result in poor performance by cracking and delamination from the coating-substrate interface. The durability of coatings thus depends on the choice of coating and substrate materials, coating deposition process, and service conditions. The design of thermal spray coatings thus requires an optimization of these parameters. This investigation provides insight into the role of coating and substrate properties on the impact resistance of coated materials, and maps the relationship between the impact resistance of WC cermet coatings on a variety of substrates. Results indicate that the delamination resistance of the coating during impact loading not only depends upon the hardness and roughness of the substrate material, but, more importantly, substrates with a higher work-hardening coefficient indicate a higher delamination resistance.
\end{abstract}

Keywords adhesion of TS coatings, cermet coatings, highvelocity oxyfuel coatings, production/preparation technology

\section{Introduction}

The quest to explore new thermal spray markets and to consolidate the existing market share requires innovative developments in the field of spray gun design, the manufacturing of spray powders, and the optimization of spray process parameters. Due to the economical and environmental edge of thermal spray processes over other overlay-coating technologies, the development of high-impact-resistance thermal spray coatings can provide a niche by not only improving coating performance in existing industrial applications, but they also have enormous potential for use in novel high-stress applications. However, the performance of thermally sprayed components in existing and new novel industrial applications relies not only on the choice of coating material, deposition process, and parameters, but also on a range of other design considerations, such as service conditions, coating thickness, functional grading, and substrate properties. Among these, the designers often have little choice about the selection of substrate material, either due to their prespecification in industrial practices (e.g., aerospace, defense, or petroleum standards) or due to cost implications. Hence, it becomes critical to comprehend the integrated performance of a given

The original version of this paper was published as part of the DVS Proceedings: "Thermal Spray Solutions: Advances in Technology and Application," International Thermal Spray Conference, Osaka, Japan, 10-12 May 2004, CD-Rom, DVS-Verlag GmbH, Düsseldorf, Germany.

S. Osawa and T. Itsukaichi, Fujime Inc., Thermal Spray Materials Dept., 82-28, Kakmihigashi-Machi-5, Kakmigahara, Gifu Pref. 5090103, Japan; and R. Ahmed, Engineering and Physical Sciences, Heriot-Watt University, Edinburgh, EH14 4AS, U.K. Contact e-mail: oosawas@fujimiinc.co.jp. coating material for a variety of substrates, such that the performance and underpinning failure mechanisms can be forecasted. With this in mind, this article reports on the results of a new generation of $\mathrm{WC}$ cermet coatings ( $\mathrm{WC}-20 \% \mathrm{Cr}_{3} \mathrm{C}_{2}-10 \% \mathrm{Ni}$ mechanically blended with $10 \% \mathrm{Ni}$ ) of improved impact resistance, and maps the influence of substrate properties on the impact resistance of the coating. It is perceived that these novel coatings of improved impact resistance will open new markets for the thermal spray industry while improving the performance of existing components (Ref 1). However, the aim of this investigation is not simply to report the achievements of improved performance, but to comprehend and combat the underpinning failure mechanisms.

\section{Experimental Test Procedure}

\subsection{Coating Deposition}

To benchmark the impact resistance of this new generation of WC cermet coatings, which is referred as W2011XJ in Table 1, the results were compared with the state-of-the-art $\mathrm{WC}-12 \% \mathrm{Co}$

Table 1 Spray powders and deposition conditions

\begin{tabular}{lcc}
\hline Coating & WC-12Co & W2011XJ \\
\hline Material composition & WC-12\%Co & $\begin{array}{c}\text { WC-20\%Cr } \mathrm{C}_{2}- \\
10 \% \mathrm{Ni})+10 \% \mathrm{Ni}\end{array}$ \\
$\begin{array}{l}\text { Powder manufacturing } \\
\text { method }\end{array}$ & $\begin{array}{c}\text { Agglomerated and } \\
\text { sintered }\end{array}$ & $\begin{array}{c}\text { Aglomerated and } \\
\text { sintered }+ \\
\text { mechanical } \\
\text { blending }\end{array}$ \\
WC grain size, $\mu \mathrm{m}$ & & 5 \\
Particle size, $\mu \mathrm{m}$ & 1 & \\
Spray conditions using & $15-45 \mu \mathrm{m}$ & 682 \\
$\quad$ JP-5000 & & 0.38 \\
Oxygen flow rate, $\mathrm{L} / \mathrm{min}$ & 893 & 380 \\
Kerosene flow rate, L/min & 0.32 & 101.5 \\
Spray distance, $\mathrm{mm}$ & 380 & 100 \\
Barrel length, mm & 203 & \\
Coating thickness, $\mu \mathrm{m}$ & 100 & \\
\hline
\end{tabular}



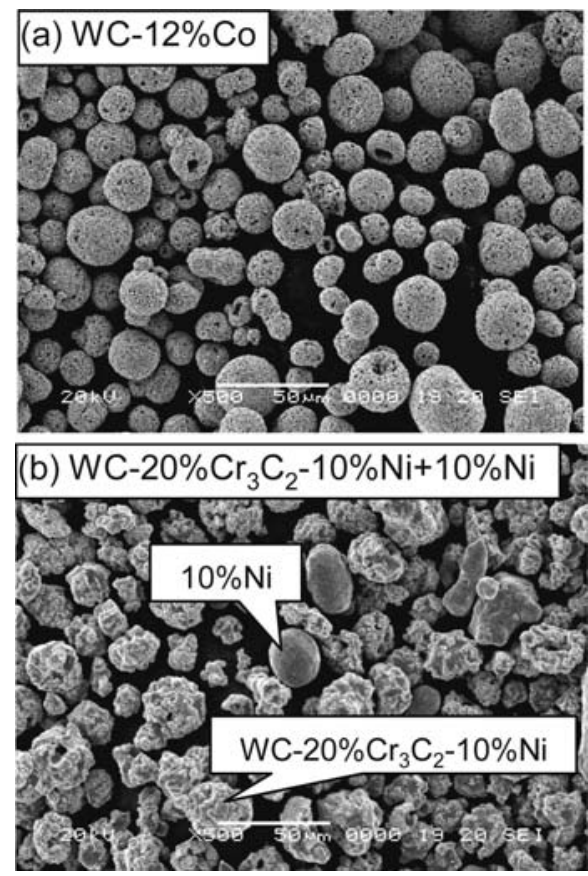

Fig. 1 SEM images of (a) WC-12Co and (b) W2011XJ powders

coatings. The coating WC- $12 \%$ Co is an agglomerated and sintered WC cermet powder with a small WC grain size $(1 \mu \mathrm{m})$, which was commercially available. The W2011XJ is blended with agglomerated and sintered $\mathrm{WC}-20 \% \mathrm{Cr} 3 \mathrm{C} 2-10 \% \mathrm{Ni}$ powder with a larger WC grain size $(5 \mu \mathrm{m})$ and atomized Ni powder with high purity. Both powders, which were manufactured by Fujimi Incorporated, (Gifu, Japan) were sprayed using a JP5000 process under the industrially optimized conditions specified in Table 1. Scanning electron microscope (SEM) images of both the reference powder (WC-12\%Co) and the W2011XJ powder are shown in Fig. 1. These coatings were produced on a variety of steel substrates, the selection of which was based either on their cost implication or industrial usage, as listed in Table 2. Prior to coating deposition, the substrate material was gritblasted using $\mathrm{Al}_{2} \mathrm{O}_{3}$ abrasive particles of 16 mesh size (average diameter $1200 \mu \mathrm{m}$ ), 40 mesh size (average diameter $430 \mu \mathrm{m}$ ), and 220 mesh size (average diameter $65 \mu \mathrm{m}$ ), respectively, using air pressure of $0.4 \mathrm{MPa}$, at an angle of $90^{\circ}$, a blast distance of 100 $\mathrm{mm}$, and a nozzle diameter of $7.0 \mathrm{~mm}$. The surface roughness of the blasted substrates was measured by a surface roughness profiler using a stylus method. The mechanical hardness of the substrates was measured using the micro-Vickers hardness tester. The coating thickness of all specimens was $100 \mu \mathrm{m}$.

\subsection{Impact Testing}

A schematic of the impact tester used in this investigation, which consists of a hopper to store and drop 500 steel balls of 9.5 $\mathrm{mm}$ diameter and $3.3 \mathrm{~g}$ weight, from a height of $1 \mathrm{~m}$, and at an angle of $60^{\circ}$ to the substrate material is shown in Fig. 2. Although all balls are released simultaneously, the guide tube (inner diameter $29 \mathrm{~mm}$ ) ensures a streamline flow of balls. This type of impact tester was selected for this investigation due to its simplicity and the reproducibility of results in ranking the rela-

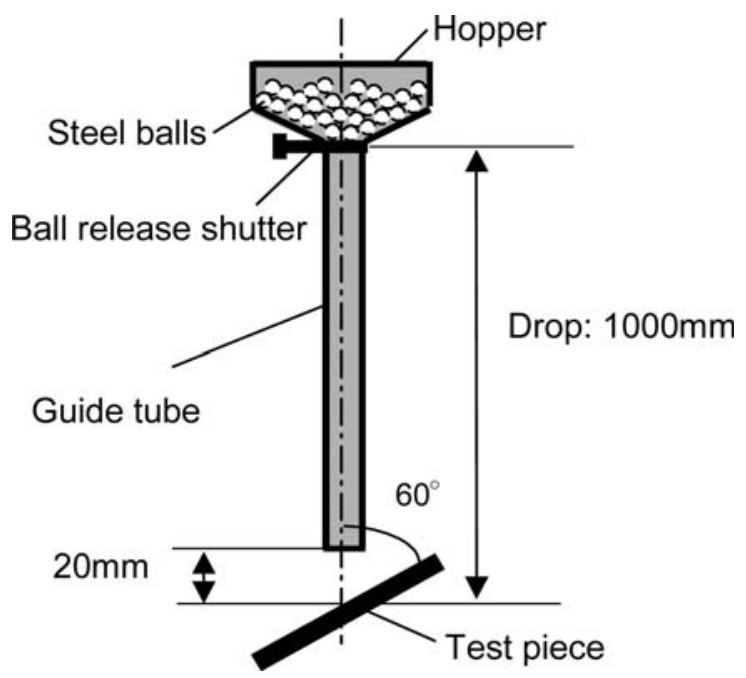

Fig. 2 Schematic of the impact tester

Table 2 Steel substrates

\begin{tabular}{ll}
\hline Mild steel & \multicolumn{1}{c}{ JIS SS400 } \\
\hline $\begin{array}{c}\text { Carbon and alloy steels } \\
\text { (annealed) }\end{array}$ & AISI $(1025,1035,1045,1055)$ \\
Carbon and alloy steels & AISI (W1-10, 4140, 4320) \\
$\quad$ AISI (1035(H), 1045(H), 1055(H)) \\
Stainless steels & AISI (W1-10(H), 4140(H), 4320(H)) \\
& AISI (304, 316) austenitic \\
Cast irons & AISI 430 ferritic \\
& AISI (440C[a]), 440C(H)[b]) martensitic \\
& Grey iron (FC300) \\
& Spheroidal graphite cast iron (FCD500) \\
High-chrom. cast iron \\
Others & (Fe-24CR-2.7C-0.7Mn-0.48SI-0.02P-0.016S) \\
& Cemented carbide (WC-14\%Co)
\end{tabular}

(a) Annealed; (b) quenched and tempered

tive performance of coatings. The experimental procedure comprises the dropping of a load of 500 balls on the coating surface and then repeating the procedure until coating failure is observed. The failure is defined when a delaminated area of more than $1 \mathrm{~mm}^{2}$ was seen by visual observation. The test was conducted four times per specimen to avoid fluctuation and to investigate the reproducibility.

The repetition of dropping 500 balls is repeated until the observation of the failure. The number of the repetition time to failure is thus defined as the impact resistance of the coating (i.e., the number of impacts to failure). To reduce the test time, if no failure is observed after 300 impact cycles, a more severe procedure with bigger steel balls can be adapted. In the current investigation, tests were suspended if no failure was observed after 300 impact cycles.

\section{Experimental Results}

The impact resistance for the WC-12Co and W2011XJ coatings is shown in Fig. 3, where the substrate is AISI1045 (annealed). These results also indicate the influence of blast material on the impact resistance of the coatings. The impact 


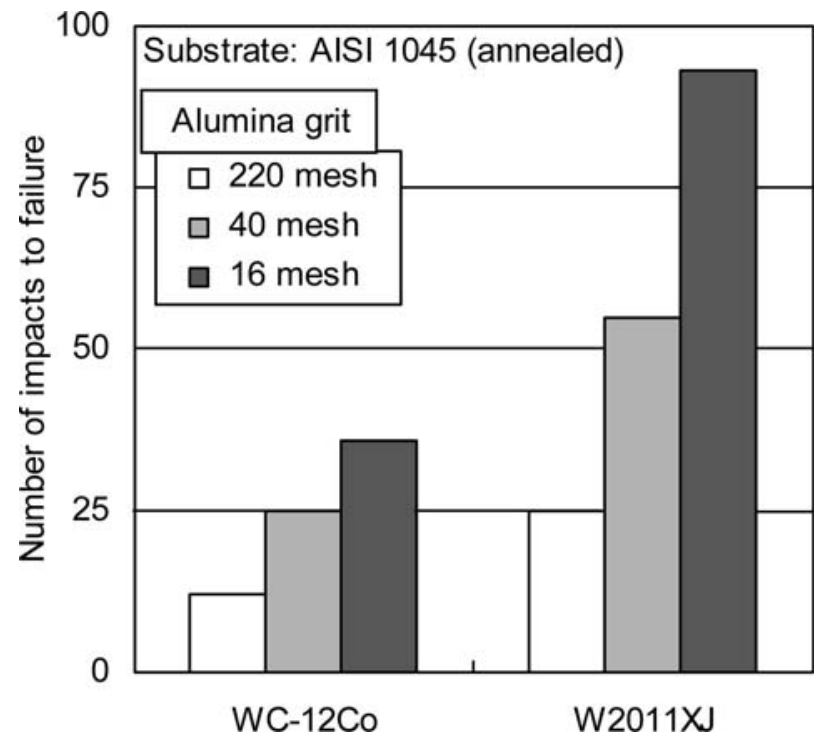

Fig. 3 Influence of blast material on the impact performance of WC12Co and W2011XJ coatings

resistance of the W2011XJ coating is more than twice that of the WC-Co coating on each blast material. Further, blasting by larger-alumina grit is effective to improve the impact resistance. The influence of the variety of steel substrates on the impact resistance of the two coating materials for the 40-mesh $\mathrm{Al}_{2} \mathrm{O}_{3}$ blast material is shown in Fig. 4. The W2011XJ coatings have higher impact resistance on every substrate. The influences of substrates as well as alumina grit size on the impact resistance of the W2011XJ coating are shown in Fig. 5. It can clearly been seen that using grit with coarser alumina is effective in improving the impact resistance of every substrate.

The influence of the quenching and tempering of the substrate material before spraying on the impact resistance of W2011XJ coatings is represented in Fig. 6. The impact resistance of the coatings is obviously improved by the quenching and tempering. The quenched and tempered W1-10 substrate shows an especially drastic improvement in impact resistance. In the case of carbon steels such as SS440, 1025, 1035, 1045, 1055 , and W1-10, the impact resistance of the coating is improved when the carbon content in the substrate is higher.

The influence of the substrate hardness of cast iron, cemented carbide, annealed and also quenched and tempered steel substrates on the impact resistance of coatings is shown in Fig. 7. As the substrate hardness increases from 100 to $650 \mathrm{Hv}$, the impact resistance tends to increase. As far as carbon steels and alloyed steels are concerned, the impact resistance increases almost linearly with increasing hardness. Cast irons and austenitic steels are way out of this linearity. Cast iron shows higher impact resistance despite its lower hardness. Remarkably, austenitic steels show a tendency that is similar to the cast iron. On the other hand, despite having hardness similar to that of carbon steels and alloyed steels, ferritic steel and martensitic steel indicated a lower impact resistance.

The results of substrate surface roughness after blasting with various alumina grits on the impact resistance of the W2011XJ cermet coatings are summarized in Fig. 8. When using larger-

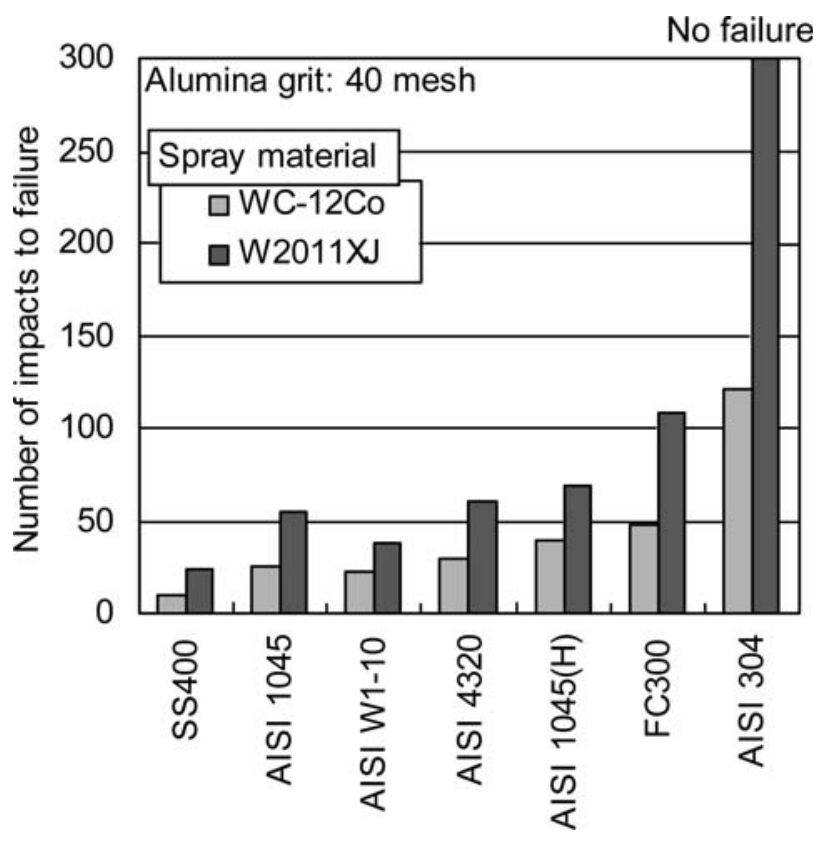

Fig. 4 Influence of substrate material on the impact resistance of WC$12 \mathrm{Co}$ and W2011XJ coatings

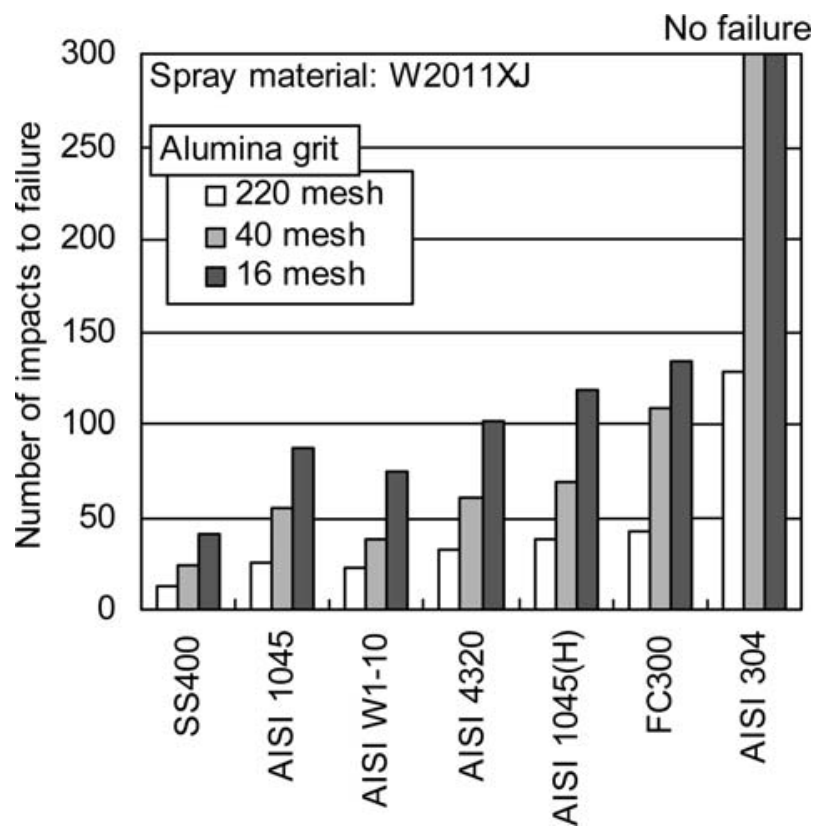

Fig. 5 Influence of substrate material and alumina grit size on the impact resistance of W2011XJ coatings

alumina grit, the surface roughness becomes coarser and the impact resistance seems to improve. On the other hand, with grit of the same alumina, the impact resistance tends to become lower with increasing surface roughness.

The influence of the grit-blasting and peening effect during high-velocity oxyfuel (HVOF) spraying on the near-surface hardness of AISI 304 and mild steel is shown in Fig. 9. At a depth of 20 to $140 \mu \mathrm{m}$ from the surface, both substrates become harder 


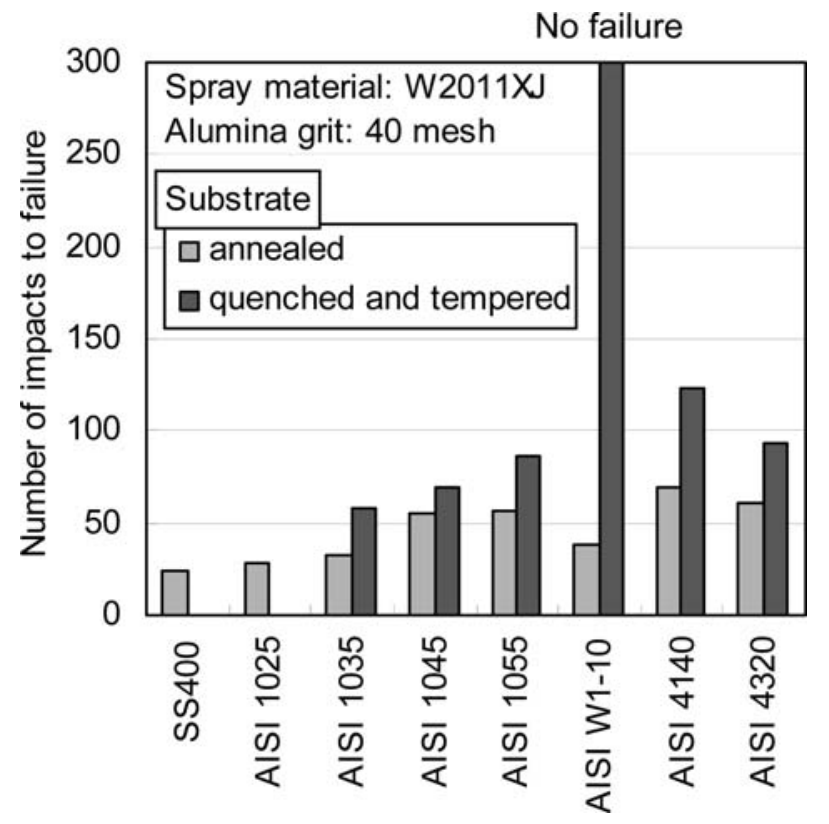

Fig. 6 Influence of substrate heat treatment on the impact resistance of W2011XJ coatings

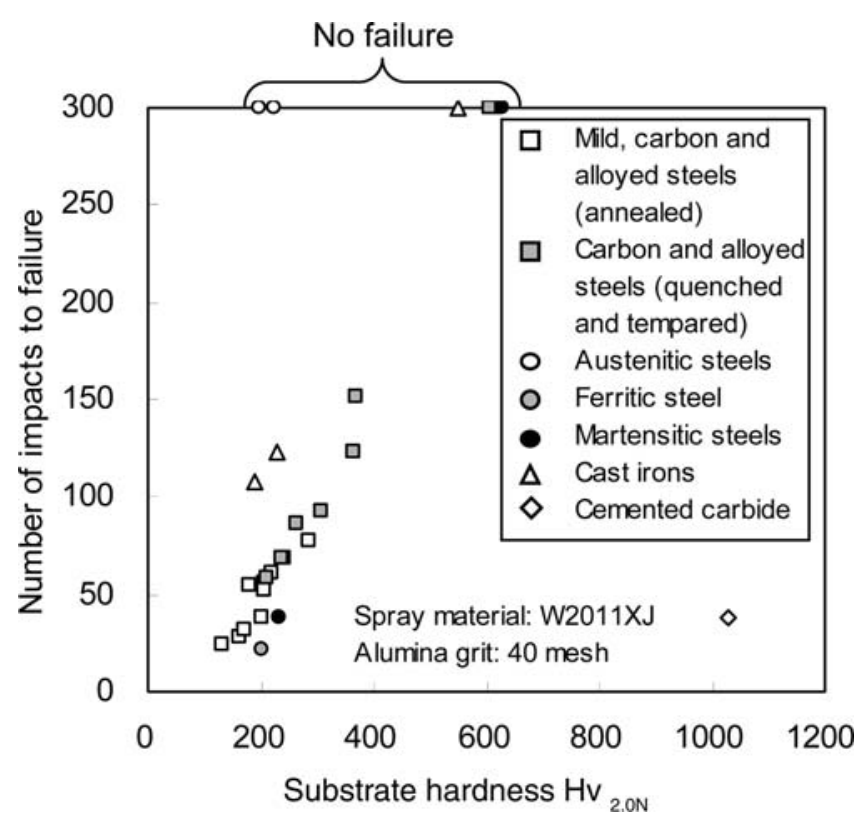

Fig. 7 Influence of substrate hardness on the impact resistance for various steel substrates

after several treatments, such as with blasting and spraying. Compared with mild steel and AISI304, the hardness of AISI304 near the surface becomes dramatically higher. In the case of the blasting, larger-alumina grit generates a surface with a higher degree of hardness.

Because it is found that the effect on the increase of the nearsurface hardness depth from $20 \mu \mathrm{m}$ on every substrate is different, the impact resistance of W2011XJ coatings as a function of the near-surface substrate hardness is represented in Fig. 10. The

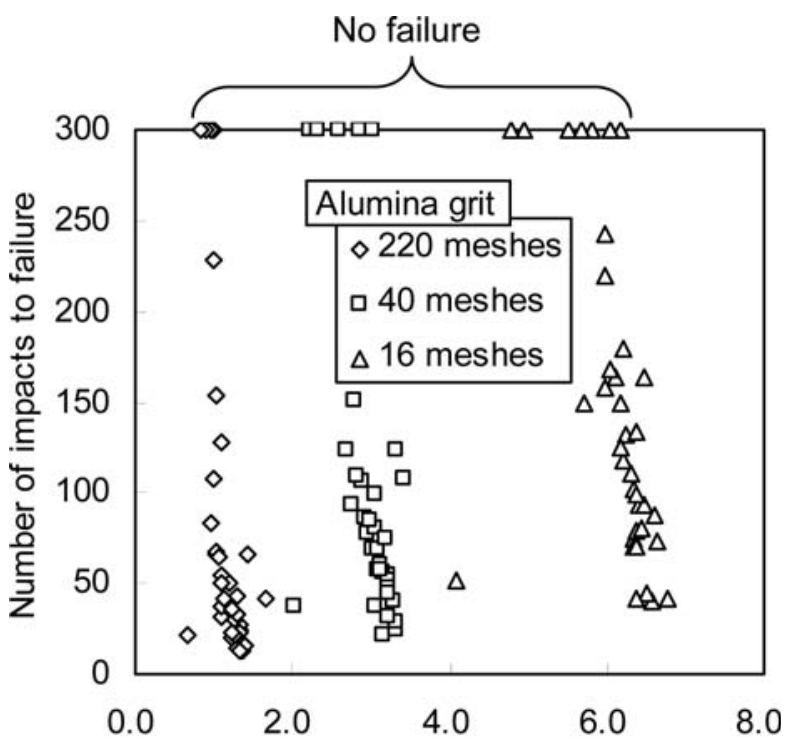

Substrate roughness $(\mathrm{Ra})$ before spraying $(\mu \mathrm{m})$

Fig. 8 Influence of substrate roughness on impact resistance after blasting with grit of various alumina

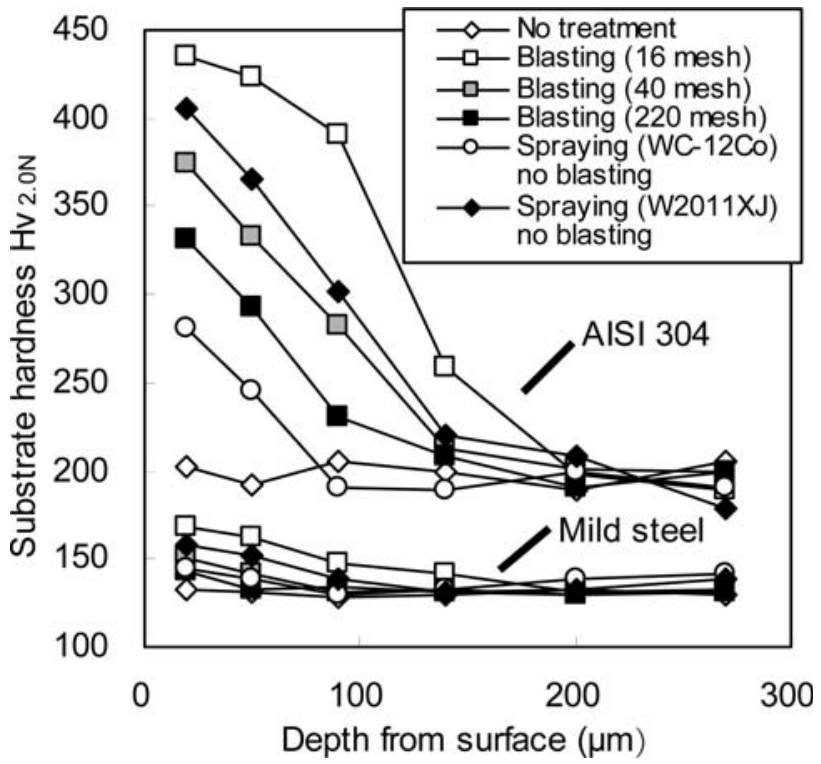

Fig. 9 Influence of grit blasting and spray peening on the near-surface hardness of substrate material

correlation between the impact resistance and the near-surface substrate hardness after blasting and spraying is almost linear between 200 and $350 \mathrm{Hv}$.

\section{Discussion}

Previous research (Ref 2) has shown that the choice of substrate material for tribologic applications of thermal spray coatings relies upon: 


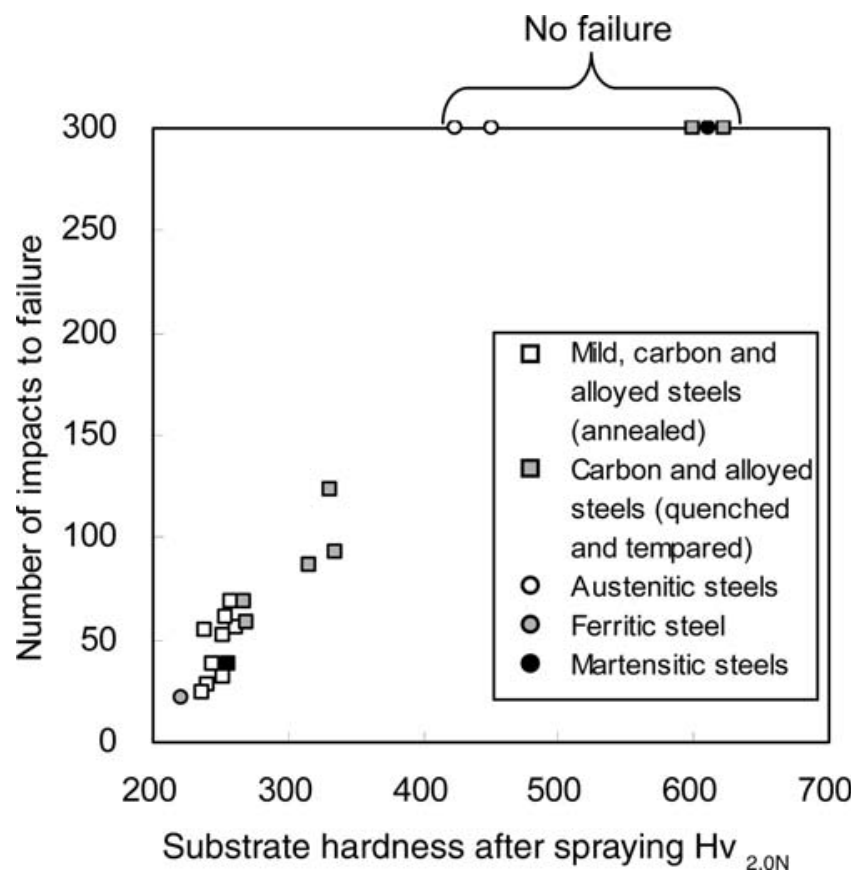

Fig. 10 Influence of the work-hardened layer hardness of various steel substrates on the impact resistance of W2011XJ coatings (alumina grit 40 mesh)

- The ability of substrate material to support the coating

- $\quad$ Plasticity during grit-blasting prior to thermal spraying to attain a critical surface roughness to provide mechanical interlock and also increased contact area

- Higher coefficient of thermal expansion compared with the coating material to generate a limited degree of compressive residual stress in the coating, to combat tensile cracking during service loading. However, too high a compressive residual stress is undesirable.

Although these design considerations provide a criterion with which to benchmark the coating design process, there are certain questions that remain unanswered. The results indicated in the previous heading highlight general anomalies in impact performance for a variety of coating and substrate combinations, some of which can be addressed as follows:

- Influence of the powder characteristics: the reason why the WC-12Co coatings do not perform as well as the coatings prepared using mechanically blended W2011XJ powder

- Influence of the mechanical state (plastic deformation) of the substrate: the relationship between the substrate hardness and the impact resistance of cermet coatings

- Influence of the substrate morphology: the influence of grit size on the impact resistance of cermet coatings

- The combined or contradictory effects of these three features: the most critical factor in achieving improved impact resistance of cermet coatings

These are considered to be important topics to understand the underpinning failure mechanism during impact loading and are discussed in the next sections.

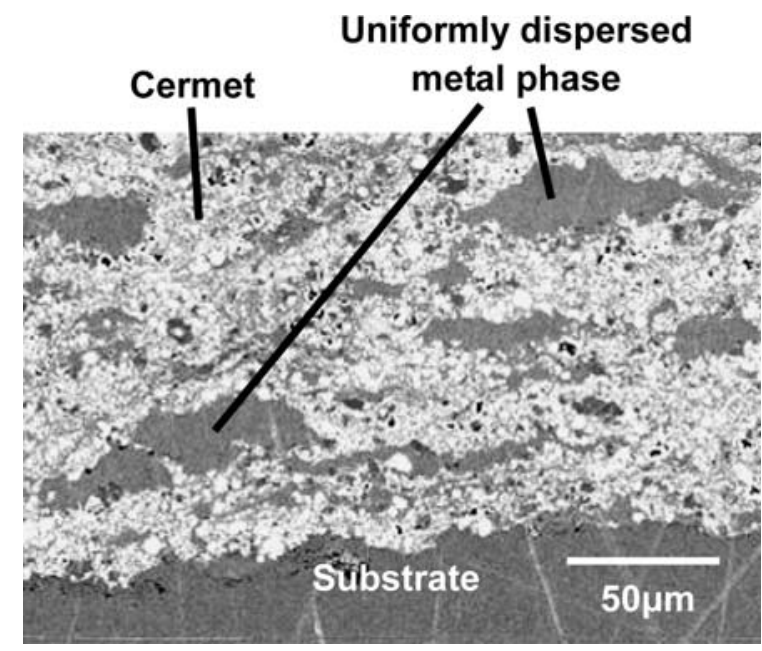

Fig. 11 Cross-sectional SEM image of the W2011XJ coating

\subsection{Influence of Coating Material on Impact Resistance}

It can be understood from Fig. 3 and 4 that the new family of W2011XJ cermet coatings results in almost twice the impact resistance when compared with the state-of-the-art WC-12Co coatings. Previous research (Ref 1 ) has also shown that W2011XJ coatings, despite having a slightly lower hardness of $970 \mathrm{Hv}$, when compared with the hardness of $1230 \mathrm{Hv}$ of the WC-12Co coatings, also show superior abrasive wear resistance to the WC-12Co coatings. But how are these improvements achieved? And more importantly, is there any further scope for improvement?

To answer these questions, it is necessary to appreciate the energy absorption and dissipation mechanism in the coating substrate system during repeated impacts. Three factors (i.e., plastic deformation, microcracking, and macrocracking) are operational to dissipate the energy absorbed during impact loading. The energy dissipation associated with the hysteresis of elastic loading and unloading during impact loading is generally small, and can therefore be neglected. To further simplify our model of energy dissipation within the coating microstructure, we can assume that the substrate is perfectly rigid and the coating is wellbonded to the substrate material. Then, to attain a higher impact resistance, we need a coating to have a relatively higher degree of plasticity, but without any drastic reduction in coating hardness. Second, to minimize the tendency of microcracks to propagate and form macrocracks under repeated impacts, a crack arrest mechanism is required. Both of these factors are operational in improving the impact energy dissipation of W2011XJ coatings. This is achieved initially by uniformly dispersing pure $\mathrm{Ni}$ particles (metal phase) within the coating microstructure, as shown schematically in Fig. 11. This provides localized plastic deformation without detrimental effects on the wear resistance. In a sense, these uniformly dispersed particles act as shock absorbers during impact loading by plastically deforming during the impact, thus absorbing a proportion of the impact energy, as if these particles get penned during impact loading.

Nevertheless, not all of the impact energy is absorbed by these uniformly distributed Ni particles, as their concentration is 
deliberately kept low due to hardness considerations. The WC$20 \% \mathrm{Cr}_{3} \mathrm{C}_{2}-10 \% \mathrm{Ni}$ component of the coating microstructure absorbs the impact energy by a combination of localized plastic deformation and microcracking. Hence, increasing the WC particle size while maintaining the overall size of the agglomerated and sintered particles increases the mean free path of the binder phase in this component of the coating microstructure. This results in a crack arrest mechanism, and a significant proportion of impact energy is absorbed at the microcrack tip, because a change in crack direction is required for it to propagate further. Hence, the synergetic effect of these factors results in improved impact resistance. However, one question remains unanswered; that is, if there is more plastic deformation in the W2011XJ coatings due to the Ni metal binder, and also a relatively lower hardness than the conventional WC-12Co coatings, how does the abrasive wear resistance increase? Although the exact mechanisms of wear in two-body and three-body abrasion of these coatings is beyond the scope of this article, it can be explained on the basis of the higher WC size in the W2011XJ coatings (Ref 3).

\subsection{Influence of Substrate Roughness}

Substrate roughness also plays an important role in improving the impact resistance of overlay coatings. During the impact loading, the coating substrate interface is subjected to a combination of compressive and shear stress. The former is critical in evaluating the ability required to support the loading (as discussed in the next section), whereas the roughening caused by the mechanical interlock at the coating substrate interface resists the crack propagation in the latter. Hence, the influence of surface roughness, as indicated for various grit sizes in Fig. 3, can also be appreciated in industrial practice. However, an examination of Fig. 8 cast doubts over this analogy, where various steel substrates are shown to achieve very high impact resistance even at lower roughness values of about $1 \mu \mathrm{m} R$ a. This paradox can be understood by appreciating that surface roughness is a threedimensional property. Hence, line traces to obtain the twodimensional roughness values can be misleading, because it is possible to have two extremely different surfaces in terms of lay and texture to have the same Ra. What is more important is the texture of the surface with respect to the impact lamella size so that the mechanical interlock is maximized, but without generating porosity due to shadowing effects caused by the complex texture of the roughness. Hence, a simple Ra value can only be used to attain an idea of the performance. The correlation between grit size and lamella size can, however, provide a better measure of the optimized surface roughness. A few other factors, which can also be appreciated from Fig. 8, are as follows:

- The threshold of minimum impact resistance increases as the surface roughness increases. This can be seen by the lower limits of the number of impacts to failure for the three mesh sizes.

- The number of the impact to failure decreases as the surface roughness increases. This can be realized by considering the higher proportion of coating substrate systems attaining a high impact resistance life (i.e., in excess of 300 impacts) for the smaller mesh size.

- Substrate roughness is not the most critical factor in attaining the improvements in impact resistance; that is, an in- crease in roughness from 2 to $6 \mu \mathrm{m} R$ a does not drastically increase the impact resistance.

\subsection{Influence of Substrate Hardness}

Substrate hardness plays a dominant role in attaining a higher resistance to impact loading, as shown in Fig. 7. Conventional wisdom dictates that the higher the hardness of the substrate, the higher should be the ability of the substrate to support the impact loading, and hence a higher impact resistance. However, as indicated in the previous section, it is the combination of hardness and roughness that yields the effectiveness to resist failure during impact loading. A typical example of this can be appreciated from Fig. 5, where the lower-mesh grit results in higher impact resistance. However, it can also be appreciated from Fig. 5 that the influence of substrate material (or its hardness) is more dominant than roughness. This requirement of synergy between hardness and roughness can also be understood from Fig. 7, where cemented carbide, despite having a very high hardness, results in relatively poor impact resistance performance, mainly because cemented carbide is not roughened enough during grit blasting when used as a substrate.

An analysis of the results shown in Fig. 7 indicates that not only is the hardness-versus-impact resistance relationship nonlinear for higher hardnesses of substrates (e.g., as explained above for cemented carbides when used as a substrate) but also some substrates with lower hardness perform as well as those of relatively higher hardness. Specifically in Fig. 7, attention is drawn to the results of austenitic steels. Hence, this nonlinearity poses a paradox: apart from surface hardness and roughness, is there another significant factor controlling the underpinning failure mechanism during repeated impact loading?

The answer to this question lies at the heart of this investigation. To understand this behavior, we need to draw our attention to the area in the close vicinity of the coating substrate interface. The tribomechanical properties of the WC cermet coating layer such as hardness, plasticity, and elastic modulus are generally very different when compared with those of the steel substrates. This mismatch in the elastic and plastic properties results in stress concentrations at the coating-substrate interface. Although variations in steel substrates will hardly result in any significant reduction in the elastic mismatch, choosing a harder steel substrate can alter the mismatch in hardness (plasticity). What is effectively required is a gradient of hardness or plasticity away from the coating-substrate interface, so that the sharp mismatch can be avoided. The answer to our question therefore lies in the ability of substrate steel to acquire this hardness gradient away from the coating-substrate interface during the spraying process. This is achieved by the work hardening of the substrate steel, first during grit blasting, and second by the peening effect during HVOF spraying. In other words, bulk hardness is not as relevant as the near-surface hardness of the substrate after spraying. This can be appreciated from Fig. 9, which shows the substrate work hardening for AISI-304 and mild steel due to grit blasting, and also due to the peening effect for the WC-12Co and W2011XJ coatings. Although the final hardness values, which will indicate the overall work hardening from both sources (i.e., grit blasting and peening during spraying), are not shown in Fig. 9 , it can be perceived that it will be higher than the single contributions shown in this Fig. 9. Similarly, higher work hardening 


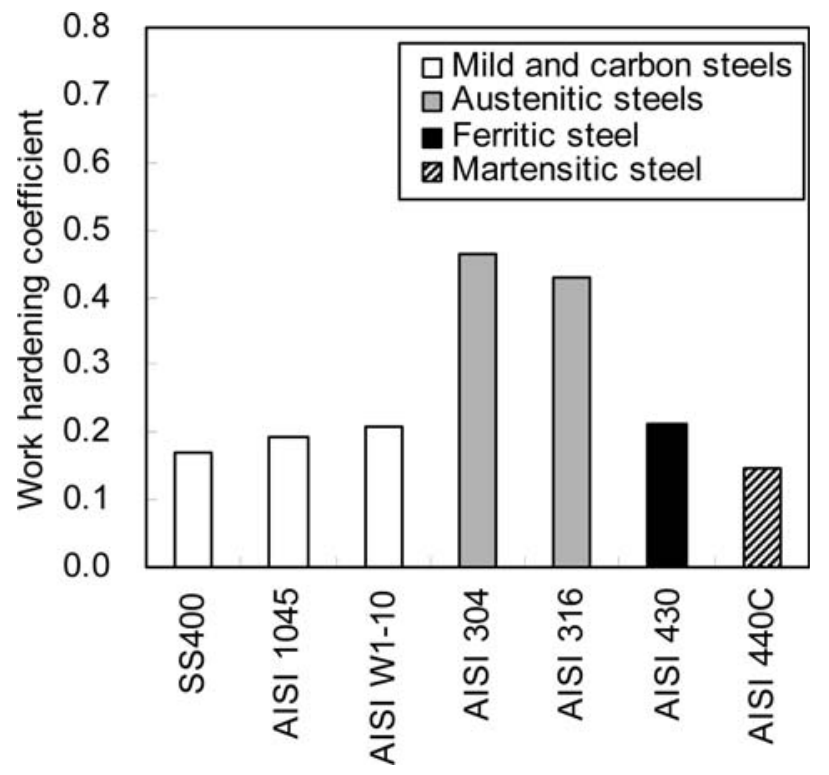

Fig. 12 Work-hardening coefficient of various steel substrates

during the HVOF peening by the W2011XJ powder in comparison to that with the WC-12Co powder can be understood from the higher carbide size of the former powder.

This is further clarified in Fig. 12, which shows the workhardening coefficient $(n)$ for various steels obtained from the compressive stress-strain curve using the relation:

$\log \sigma=\log F+n \log \varepsilon$

where $F$ is the applied load, $\sigma$ is the stress, and $\varepsilon$ is the strain (Ref 4). The higher work-hardening coefficient thus resolves the bulk hardness paradox seen in Fig. 7, on the basis of the workhardened layer, as shown in Fig. 10.

\section{Conclusions}

- For the variety of steel substrates considered in this investigation, it is concluded that, apart from the bulk substrate hardness, the near-surface hardness of the substrate resulting from the work hardening caused by peening during the grit blasting and HVOF spraying plays a dominant role in improving the ability of the substrate to support the coating, and thus in improving the integrated coating substrate performance during impact loading.

- $\quad$ Optimized blending of metal and cermet powders can significantly improve the impact resistance of cermet coatings.

- The synergy between the surface roughness and hardness of the substrate material enables optimization of the coating impact resistance.

\section{References}

1. T. Itsukaichi and S. Osawa, Development and Application of WC$\mathrm{Cr}_{3} \mathrm{C}_{2}$-Ni Coating with High Impact Resistance, Thermal Spray 2003. Advancing the Science and Applying the Technology, B.R. Marple and C. Moreau, Ed., May 5-8, 2003 (Orlando, FL), ASM International, 2003, p 237-242

2. R. Ahmed, Rolling Contact Fatigue, Analysis and Prevention, Vol 11, ASM Handbook, Section 6E, ASM International, 2003, p 941-956

3. S. Osawa, S. Tawada, N. Kato, and T. Itsukaichi, Influence of WC Particle Size on the Properties of Carbide Coatings, Proceedings of Annual Meeting, Japan Thermal Spray Society, Vol 73, 2001, p 39-40 (in Japanese)

4. M. Ohring, Engineering Materials Science, Academic Press, 1995 